\title{
DESAFIOS DO "PRECONCEITO ETÁRIO" NO BRASIL"
}

\author{
Ana Maria Goldani*
}

RESUMO: Os fluxos de recursos materiais e simbólicos e as obrigaçōes entre geraçōes marcam de forma importante os membros da família e a sociedade em geral. As possibilidades de trocas intergeracionais aumentam com a longevidade humana e hoje ganham destaque nas agendas acadêmicas e de políticas públicas. Concorrentemente, o preconceito etário e a discriminação por idade emergiram como assuntos importantes. Este artigo busca, principalmente, chamar a atenção para essas questôes e sua relação com o debate político atual sobre a alocação de recursos por grupos etários. Argumentamos que o preconceito etário e a prática da discriminação por idade no Brasil deveriam ser vistos como parte das múltiplas formas de discriminação experimentadas pelos indivíduos. Entendemos, também, que noticiar a idade de alguém não seria inerentemente ofensivo, mas agir a partir de estereótipos baseados na idade funciona claramente contra o indivíduo. Este trabalho documenta o impacto do preconceito etário e das relaçōes intergeracionais na vida das pessoas e aponta para sua importância na formulação de políticas públicas.

Palavras-chave: Preconceito etário. Discriminação por idade. Relações entre gerações. Políticas públicas.

\section{The Challenges of Ageism IN BRAZIL}

ABSTRACT: The material and symbolic resource flows and obligations between generations leave an indelible imprint on family members. These intergenerational exchanges have increased in

\footnotetext{
* Tradução de Alain François, com revisão técnica de Carolina Peres.

** Doutora em Sociologia e professora da Princeton University (EUA).

E-mail: agoldani@princeton.edu
} 
recent years with growing human longevity and they thus have become important to current academic and policy agendas. Concurrently, ageism and age discrimination have emerged as important subjects. The main goal of this article is to call attention to these issues and their relationship with the current policy debate on resource allocation by age groups. We argue that ageism and the practice of age discrimination in Brazil should be viewed as part of the multiple forms of discrimination experienced by individuals. While noticing someone's age is not inherently offensive, acting on age-based stereotypes clearly works against the individual and often goes unchallenged by mainstream society. A central assumption in this paper is that the way we frame ageism and intergenerational relations significantly affects public policies.

Key words: Ageism. Age discrimination. Intergenerational relations. Public policy.

\section{Introdução}

Não sei por que ela deveria revelar sua idade. A Ana Botafogo, por si só, é eterna. A maior expressão do balé clássico brasileiro e internacional. Suas apresentações sempre nos encheram de êxtase e orgulho. Talentos assim não têm idade. São sempre como os vemos, e pronto. Que mania desses repórteres brasileiros de misturarem matérias que poderiam ser excelentes, com perguntinhas de baixo nível, remetendo ao fuxico. (Fabio Zonzini) $)^{1}$

P

caráter contencioso da idade surge claramente na citação acima e revela a ambiguidade de Zonzini a respeito da percepção do envelhecimento e dos indivíduos idosos. Essas expressōes do preconceito etário e as práticas a elas relacionadas são comuns na mídia e na sociedade brasileira. Especificamente, a citação acima reflete uma ideia comum de que nossos julgamentos sociais cotidianos costumam se basear na idade, mesmo se o negamos conscientemente (MacNicol, 2006). Outro exemplo é a revelação regular da idade depois do nome de uma pessoa, no jornalismo brasileiro. Argumentamos que a discriminação por idade e os estereótipos são problemas que a sociedade deve enfrentar e eliminar através da conscientização, da educação e de intervençôes políticas apropriadas. Os esforços nesse sentido têm ganhado 
ímpeto nas sociedades industrializadas, onde a discriminação por idade é uma questão altamente atual num pano de fundo de preocupações com a crescente longevidade e a duração das carreiras profissionais. Pela primeira vez, essa forma de discriminação foi tornada ilegal na União Europeia e, consequentemente, hoje, cada Estado-membro adotou leis nesse sentido (Sargeant, 2008). ${ }^{2}$

Como em muitas sociedades ocidentais, o preconceito etário, no Brasil, ocorre nas famílias, nos órgãos governamentais, no sistema de saúde, nos mercados de trabalho assalariado e em toda a mídia. Muitos regulamentos e programas governamentais são estabelecidos tendo um dado grupo etário em mente e, muitas vezes, discriminam inadvertidamente pessoas dos outros grupos etários. ${ }^{3}$ Os programas de permanência no emprego são citados como um bom exemplo desse tipo de discriminação, pois costumam ser dirigidos a pessoas com idades "empregáveis" ou com um status específico em termos de gênero, raça ou deficiência (Sampaio, Navarro \& Martín, 1999). As políticas sociais brasileiras voltadas aos idosos, às crianças, aos jovens e às mulheres em idade reprodutiva podem ser vistas como preconceituosas. Por isso, a ideia de que a idade é uma base potencial de divisão e conflito entre gerações, enquanto tal, representa uma ameaça à solidariedade intergeracional e é uma questão que está sendo discutida no Brasil (Barros \& Carvalho, 2003; Turra \& Queiroz, 2009; Goldani, 2005; Neri, 2003).

Crenças e atitudes preconceituosas em termos de idade podem não ser prejudiciais em si e por si. Contudo, a discriminação por idade ocorre se essas crenças e atitudes legitimam "o uso da idade cronológica para demarcar classes de pessoas a quem são sistematicamente negados recursos e oportunidades de que outros desfrutam, e que sofrem as consequências desse menosprezo, que vão do patrocínio bem-intencionado ao aviltamento inequívoco" (Bytheway, 2005, p. 14). Trata-se do preconceito supremo, da última discriminação, da mais cruel rejeição e do terceiro maior "-ismo", ${ }^{4}$ após o racismo e o sexismo (Palmore, 2004). Como o racismo, o preconceito etário depende da estereotipagem. Sente-se o seu impacto destruidor em três áreas principais: preconceito social, discriminação nos locais de trabalho e tendenciosidade no sistema de saúde (Butler, 1980).

O preconceito social é vinculado ao envelhecimento e é subjacente à maioria das formas de preconceito etário. Por exemplo, a veneração 
da juventude pela maioria das sociedades ocidentais costuma fazer do envelhecimento um objeto de vergonha, ridículo, de desgosto. Em indústrias extremamente voltadas para os jovens, como o entretenimento e a tecnologia computacional, os funcionários que já passaram dos 30 anos são vistos como "acabados". Nos locais de trabalho, funcionários mais velhos, às vezes, não são contratados ou promovidos porque os patrôes costumam acreditar que serão menos flexíveis e competentes do que aqueles mais novos. Num sistema que valoriza o lucro acima de tudo, os empresários costumam optar por substituir funcionários mais velhos, mais experimentados e mais bem pagos por uma mão de obra mais barata e mais jovem. Finalmente, na área da saúde, os profissionais, por vezes, ignoram ou desconsideram as queixas crônicas dos idosos, preferindo enfocar questões de saúde mais agudas em pacientes mais novos. Um dos resultados mais nítidos da tendenciosidade na saúde brasileira foi o aumento de casos de pacientes HIV positivo entre os mais velhos, pois os programas de combate à AIDS são essencialmente destinados a pessoas jovens ou de meia-idade e ignoram os idosos, partindo do princípio de que não são sexualmente ativos (Valente, 2008).

A sociedade brasileira, que é altamente estratificada em termos etários e consciente do valor das diferentes idades, adota atitudes complexas e variáveis para com os seus cidadãos mais velhos. O preconceito social é a área mais estudada, seguido por uma postura tendenciosa em relação à idade no sistema de saúde e pela discriminação etária nos locais de trabalho. A maior parte desses estudos é de autoria de profissionais da saúde, gerontologistas e psicólogos sociais, que enfocam a percepção negativa e a discriminação das pessoas mais velhas (ver, entre outros, Couto, 2009; Cachioni \& Aguilar, 2008; Souza, 2003; Von Simson, Neri \& Cachioni, 2003; Neri, 2003, 2005; Debert, 1999; Freitas et al., 2002; Veloz, Nascimento-Schulze \& Camargo, 1999).

Argumentamos que o debate sobre discriminação por idade e preconceito etário, no Brasil, deveria ocorrer sob a abordagem das discriminações múltiplas. Esta exige que consideremos a perspectiva da interseccionalidade, que abrange a ideia de que pessoas podem experimentar opressão e privilégio ao mesmo tempo, com base em certas características individuais e dependendo do contexto. Em alguns casos, a intersecção entre o sexo, a raça, a idade ou a deficiência pode se sobrepor e, juntos, produzir efeitos únicos que criam, como sugere TowsendBell (2009), "minorias discretas e insulares", socialmente desfavorecidas 
por causa dessas características. Outras vezes, qualquer uma dessas características pode se somar a outras, como assistência social, status familiar, econômico, social e de classe, a fim de criar experiências únicas para os indivíduos. Mesmo quando combinado a outros aspectos, como a assistência social e o status familiar, o alcance da discriminação pode não ser revelado por uma abordagem tradicional, não interseccional (Towsend-Bell, op. cit.). A abordagem interseccional da discriminação se vincula a uma tradição sociológica de estudos sobre raça, gênero e classe que ganhou relevância entre as feministas negras norte-americanas, nos anos de 1980, que a melhoraram e propagaram a sua discussão (Collins, 2000; Crenshaw, 1995). ${ }^{5} \mathrm{~A}$ interseccionalidade também ganhou mais visibilidade na área dos direitos humanos e se mostrou instrumental para discutir queixas em foros internacionais.

Finalmente, afirmamos que o preconceito etário e a discriminação por idade são partes importantes do processo de transmissão intergeracional de conhecimentos. A transmissão de conhecimentos e a educação, que permeiam as relações entre pais e filhos ou avós e netos, têm dois aspectos fundamentais que são insuficientemente considerados nos estudos sobre as relações intergeracionais: a probabilidade crescente de experimentar relaçôes intergeracionais, em razão do aumento da esperança de vida humana, e a subsequente transferência de recursos materiais e simbólicos entre avós, pais e filhos/netos, dos mais velhos aos mais novos e dos mais novos aos mais velhos. Esses elementos representam novas oportunidades de aprendizagem fora do sistema educacional formal. Este estudo chama a atenção para o fato de que o novo sistema de ensino e aprendizagem entre gerações afeta não apenas o processo interpessoal de trocas entre as geraçôes, conhecido como "contrato intergeracional implícito", como também as políticas públicas e os contratos de gênero.

Portanto, este artigo busca transmitir, primeiro, que o preconceito etário no Brasil está principalmente associado a idosos e é uma questão central no debate sobre trocas intergeracionais e a alocação de recursos governamentais; segundo, que a discriminação por idade deveria ser combatida com programas educacionais, intervenções do governo e até mesmo uma nova legislação. Enfrentando a tensão tradicional entre academismo e ativismo, concluiremos com recomendações para identificar e enfrentar a discriminação por idade e o preconceito etário no contexto das atuais políticas antidiscriminatórias no Brasil. 
A experiência brasileira a partir de várias perspectivas

No Brasil, o "conflito entre as geraçôes", seja ele real ou inventado, chegou ao centro das discussões políticas sobre a população idosa e ao público em geral através da mídia (Goldani, 2005). Na abordagem desta questão predominou o "debate sobre equidade intergeracional”, cuja premissa é de que as divergências entre segmentos etários específicos de uma população são bem marcadas e que as geraçôes mais jovens, médias e mais velhas estáo competindo entre si por recursos escassos. Esta perspectiva ganhou força com os debates nacionais e internacionais sobre reformas da Previdência e o aumento das despesas sociais, nos anos de 1990.

Ao mostrarmos como o debate sobre a relação "injusta" entre grupos etários continua influenciando a discussão sobre políticas públicas no Brasil e a importância de oferecer alternativas como contrapeso à visão estreita da "equidade intergeracional", ${ }^{6}$ analisaremos, primeiro, uma pergunta da Pesquisa Mundial de Valores (World Value Survey - wVs): "Em tempos de empregos escassos, deveríamos forçar os mais velhos a se aposentar mais cedo?". Em segundo lugar, discutiremos um trabalho recente que se preocupa com a saúde financeira da Previdência no contexto das mudanças demográficas brasileiras (Turra \& Queiroz, 2009).7

Em tempos de empregos escassos, deveríamos forçar os mais velhos a se aposentar mais cedo?

Os dados da wvs para o Brasil mostram que as cifras de apoio a esta pergunta duplicaram, passando de 33\% em 1991 a 66\% em 1997. Este aumento, na percentagem de brasileiros que concordam que os idosos deveriam ser forçados a se aposentar em tempos de escassez de empregos, indicaria certa discriminação por idade. As razōes para isso não foram captadas pela pesquisa, mas tratamos de avaliar o peso das características individuais e dos fatores contextuais para explicar a forte mudança de opinião em um curto espaço de tempo.

Nossos resultados, de uma análise estatística multivariada, mostram que a educação e a renda estáo negativamente associadas a atitudes a respeito da aposentadoria forçada, quando comparadas com outras variáveis. ${ }^{8}$ Isso demonstra que pessoas com menos educação e renda 
inferior estão mais propensas a apoiar a aposentadoria forçada dos idosos. Quando analisamos os dados de 1991 e 1997 em conjunto, a probabilidade prevista de concordar com a aposentadoria forçada dos idosos em tempos de desemprego é de $60 \%$ para pessoas com níveis de educação inferiores, mas ela cai para $42 \%$ e $25 \%$ para indivíduos com níveis de educação médio e alto, respectivamente. Em termos de renda, a probabilidade prevista de concordar com a aposentadoria forçada é de $51 \%$ para os indivíduos da parte mais baixa da escala de renda, contra $24 \%$ para os indivíduos da sua parte mais alta. Análises separadas daqueles dois anos mostram que o apoio para a aposentadoria precoce era mais alto em 1997, quando outras variáveis se mantinham constantes. Ou seja, o padrão das respostas não variou segundo as outras características individuais inclusas no modelo, tais como: idade, sexo, cor da pele e estado civil.

O crescimento da opinião pública negativa quanto aos idosos deve, também, ser entendido no contexto brasileiro das desigualdades econômicas e sociais dos anos de 1990 e das estimativas de crescimento da população de mais de 60 anos, projetadas para triplicar seu peso relativo no total nos próximos 40 anos, de $10 \%$ para $30 \%$ entre 2010 e 2050 (IBGE, 2008). Outro elemento contextual importante e relacionado a tudo isso seria o debate sobre os gastos sociais do governo e a reforma da Previdência nos anos de 1990. A abordagem predominante neste debate, apresentada por economistas e divulgada pela mídia, sustentava a competição e o conflito entre gerações por recursos escassos. Isso potencializou o conhecimento e a formação de opinião sobre o chamado "debate da equidade intergeracional", largamente utilizado nos Estados Unidos (Barros, Mendonça \& Santos, 1999; Barros \& Carvalho, 2003; Giambiagi, 2004; Lavinas \& Garson, 2003). Este debate ocupou as manchetes dos diferentes tipos de mídia e, certamente, influenciou a opinião dos indivíduos sobre a disputa por recursos escassos (Goldani, 2005; Neri, 2003).

Mesmo não tendo dados para medir o impacto dos diferentes discursos sobre o aumento da opinião negativa daqueles que, no Brasil, concordam que os idosos deveriam ser forçados a se aposentar em tempos de escassez de empregos, gostaríamos de chamar a atenção para o fato de que pesquisas em outros países sugerem que diferentes tipos de mídias ajudam a aumentar as percepçóes negativas contra os idosos. Nos Estados Unidos, estudos que examinam como pessoas 
jovens, de meia idade e idosas respondem às informações de uma fonte de mídia sobre a vantagem ou desvantagem econômica relativa do seu grupo etário mostram que apresentar as comparações intergeracionais como favoráveis ou desfavoráveis para um grupo etário afeta as atitudes para com a idade e o apoio a gastos baseados em aspectos etários. Logo, é razoável esperar que, no caso brasileiro, isso também possa ter ocorrido e seja parte da explicação da percentagem mais elevada de brasileiros favoráveis à aposentadoria precoce dos idosos em 1997.

Concluindo, algumas estatísticas secundárias também reforçam o nosso argumento de que fatores contextuais influenciaram as respostas negativas dos brasileiros sobre a aposentadoria precoce dos idosos em momentos de escassez de empregos. Por exemplo, as duas reformas do sistema previdenciário brasileiro, em 1993 e 1999, afetaram as áreas de seguro social, assistência social e saúde e contribuíram para uma expansão da cobertura da Previdência. A percentagem de pessoas aposentadas com 60 anos ou mais aumentou de 59\% para 92\% nas áreas rurais e de 49\% para 68\% nas áreas urbanas, entre 1981 e 2001 (Wajnman et al., 2005). Os benefícios de aposentadoria tornaram-se uma importante fonte de renda para as famílias e ajudaram a combater a pobreza. Entretanto, a percentagem de atividade dos idosos não caiu. Antes, a dos homens idosos passou de $36 \%$ para 38\% nas áreas urbanas, embora permanecesse em $60 \%$ nas áreas rurais, ao passo que a da atividade feminina aumentou de $9 \%$ para $12 \%$ nas áreas urbanas e de $13 \%$ para $19 \%$ nas áreas rurais (idem, ibid.). Portanto, o aumento de benefícios previdenciários e a continuada participação dos idosos no mercado de trabalho, bem como a maior conscientização pública da disputa por recursos entre grupos etários, emergem como fatores explicativos da duplicação na percentagem de brasileiros que apoiam a ideia de que pessoas idosas deveriam ser forçadas a se aposentar mais cedo, quando os empregos são escassos. ${ }^{?}$

\section{Como a discriminação está vinculada às mudanças demográficas no Brasil?}

A partir de uma perspectiva demográfica aparentemente neutra, a dos chamados "dividendos demográficos" ou da "janela de oportunidade" - que enfatizam as vantagens das mudanças da estrutura etária para o desenvolvimento econômico -, Turra e Queiroz (2009) chamam 
a atenção para as "desigualdades geracionais" no Brasil. Alegam que os idosos foram os maiores beneficiários da reforma da Previdência, por causa de políticas mal concebidas e que não consideram as oportunidades temporárias oferecidas pela transição demográfica. De acordo com os autores, o Brasil está perdendo a sua "janela de oportunidade":

En 2004, los sistemas públicos de pensiones del Brasil transfirieron alrededor del $12 \%$ del PIB de la población en edad de trabajar a los ancianos, un monto significativo para un país donde tan solo el $6 \%$ de la población tienen más de 65 años (...). Las conclusiones revelan que los encargados de formular las políticas en el Brasil han tomado decisiones que no están bien fundadas en una base técnica y no tuvieron en cuenta la naturaleza temporaria de las transiciones demográficas (...). Esta miopía también ha reducido los beneficios fiscales que se derivan de los aumentos de la mano de obra disponible. (...) las simulaciones de políticas indican que mediante el aumento de la edad mínima de jubilación y la eliminación de la evasión, entre otros factores, se podría aumentar las tasas de dependencia de la seguridad social, ayudar a cumplir con las obligaciones, mantener a la población anciana por encima de la línea de pobreza y crear las condiciones necesarias en el futuro para el crecimiento economico al: i) generarse superavit en el capital humano y ii) aliviarse la carga que debn encarar las generaciones futuras (...). (Turra \& Queiroz, op. cit., p. 162-163)

Partindo do pressuposto maior deste artigo - de que a maneira como formulamos o preconceito etário e as relações intergeracionais tem um efeito significativo tanto sobre a discriminação por idade percebida, quanto sobre o apoio a programas sociais baseados na idade -, apresentamos uma análise alternativa para alguns dos argumentos de Turra e Queiroz. Sustentamos que a associação entre mudanças na estrutura etária e nas finanças da Previdência, posta no cerne dos fracassos dos dividendos demográficos, merece um modelo de análise mais complexo, que incorpore vários elementos da relação entre grupos etários e não apenas o nível de despesas públicas. Entre esses elementos, discutiremos três: 1) a necessidade de situar as despesas públicas da rede de proteção social para diferentes grupos etários no contexto amplo das desigualdades sociais e econômicas; 2) a necessidade de considerar os princípios sobre os quais o amparo público é oferecido e 3) a necessidade de informações apropriadas sobre o setor de cuidados e sobre as necessidades e o acesso a outros dos diferentes grupos etários. 
Primeiro, esquecer de inscrever a discriminação por idade dentro do sistema mais amplo de desigualdades não apenas limita o entendimento da complexidade do processo de tomada de decisóes políticas, como também pode levar a conclusões enganadoras sobre o impacto das políticas. De fato, os assim chamados "privilégios" atuais dos idosos brasileiros devem ser vistos nos níveis macro e micro, pois não apenas melhoram o seu bem-estar pessoal, como também fornecem recursos para a sua família extensa. Mais de dois terços da população com 60 anos ou mais estavam recebendo algum tipo de benefício de pensão $(77 \%)$ em 2002, o que representava uma parte substancial da renda familiar. A renda de idosos que vivem com outros membros da sua família representava quase $60 \%$ do total da renda familiar, em áreas urbanas, e $70 \%$, em áreas rurais (Wajnman et al., 2005). Com efeito, existe um fluxo inverso de transferências intergeracionais dos idosos para os jovens, o que revela as dificuldades econômicas enfrentadas por estes últimos (Camarano, 2005). Portanto, reconhecer a desigualdade de um grupo etário como sendo parte de um sistema múltiplo de discriminação, ou em termos de outros "-ismos", no Brasil, exige manter em mente a complexidade de intersecçôes, como ser "velha, feminina, pobre e negra". Este é apenas um exemplo dos vários retratos recentes de brasileiros sob múltiplas desigualdades (Pinheiro et al., 2008). Nesse sentido, um sistema integrado de políticas, que leve em conta a complexidade histórica das desigualdades entre grupos no país, parece ser o modo mais apropriado de analisar os benefícios da Previdência e a sua repartição entre os grupos etários.

Uma segunda questão tem a ver com reconhecer os princípios constitucionais que regem a alocação do amparo público. As políticas públicas são orientadas tanto por uma lógica técnica, quanto pela habilidade de grupos para pressionar o Estado. O sistema de previdência brasileiro é claramente um resultado da pressão de diferentes grupos durante a elaboração da Constituição Nacional de 1988, que nortearam as reformas do sistema e melhoraram os direitos dos cidadãos. Exige-se do governo que este faça cumprir os princípios constitucionais através de leis e políticas e, com a participação de sociedade civil, crie um conjunto de políticas públicas que são redistributivas e reconhecem diversos interesses.

Um exemplo polêmico da natureza da rede previdenciária brasileira tem a ver com o caráter não contributivo dos benefícios. Por 
exemplo, o Benefício da Prestação Continuada (BPC) garante um salário mínimo por mês a pessoas com mais de 65 anos e a deficientes, cuja família tem uma renda per capita inferior a um quarto de salário mínimo. ${ }^{10}$ Portanto, à medida que novos grupos de beneficiários emergem e as despesas sociais aumentam, a estrutura de relação e poder entre grupos sociais e etários parece ter mudado e ameaçar os privilégios tradicionais. Assim, não apenas questões técnicas e conjunturais, como as que dizem respeito a "dividendos demográficos", mas também as garantias constitucionais de negociação entre segmentos da sociedade e o Estado devem ser consideradas no debate e elaboração de políticas públicas no Brasil.

Quanto à questão das informações apropriadas, tanto sobre cuidados sociais e outros usos de serviços, quanto sobre o acesso e as necessidades de diferentes grupos etários, a limitação dos dados disponíveis e sua natureza transversal são muito conhecidas no Brasil. O relatório de despesas sociais do governo central, por exemplo, descreve as fontes de receita do governo e suas despesas sociais por área e informações detalhadas. Embora tenha servido como fonte principal para enfocar a tendenciosidade geracional nas despesas sociais, esta base de dados limita as análises a uma "metodologia estática da realidade atual" e ignora as dinâmicas de chances de vida do cidadão. Nesse sentido, vale lembrar que "a questão central do bem-estar não é quantas pessoas, num dado momento, estão mal pagas ou mal alojadas, mas quantas, provavelmente, continuarão a ser mal pagas ou mal alojadas de modo persistente" (Esping-Andersen et. al., 2002, p. 6).

Em conclusão, gostaríamos de sugerir que a avaliação do impacto de programas sociais voltados ao bem-estar da população de uma certa idade deveria servir de contraponto à avaliação de estudos preocupados com as "finanças do sistema de previdência e os privilégios dos mais velhos". ${ }^{11}$ De fato, alguns resultados recentes da expansão da cobertura, qualidade e eficiência do sistema de previdência sugerem uma série de benefícios para diferentes grupos etários no Brasil. Da mesma forma, o aumento da escolaridade feminina, a elevação do percentual de domicílios com saneamento básico adequado (esgotamento sanitário, água potável e coleta de lixo) e o acesso aos serviços de saúde contribuíram para a queda da taxa de mortalidade infantil em todo o país. Estimada em 23,3 óbitos de menores de 1 ano para cada mil nascidos vivos, em 2008, esta taxa ainda é alta quando comparada com os 
países vizinhos do cone sul para o período 2005-2010 (Argentina: 13,4 por mil; Chile: 7,2 por mil; Uruguai: 13,1 por mil) (IBGE, 2008).

Outros resultados positivos de programas sociais de prioridade máxima, como o de criação de empregos para os jovens ("Primeiro Emprego"), o de unificação dos programas de transferência de renda condicional para a redução da pobreza ("Bolsa Família"), também deveriam ser considerados. Avaliaçôes recentes sugerem que estes resultados, juntamente com a recuperação do poder de compra do salário mínimo, contribuíram para tornar menos vulneráveis os brasileiros mais pobres. Portanto, para traçar um retrato e obter um entendimento mais completo dos efeitos das políticas entre diferentes grupos etários, precisamos de uma diversidade de abordagens conceituais e metodológicas mais amplas, que não se limitem ao enfoque da "equidade entre as gerações", como, por exemplo, a abordagem das capacidades, de Amartya Sen (1999, 2006). ${ }^{12}$

\section{Qual é a extensão da discriminação no Brasil?}

Apesar das garantias constitucionais, a discriminação faz parte do cotidiano dos brasileiros em vários cenários e em diferentes níveis. A discriminação por idade no mercado de trabalho é mal conhecida, mas os resultados disponíveis indicam claramente a sua presença, mesmo dentro de um grupo já discriminado, como os trabalhadores incapacitados (Sampaio, Navarro \& Martín, 1999). Em 2005, mais de um quarto dos homens entre 50 e 65 anos e 30\% das mulheres entre 50 e 59 anos eram definidos como economicamente inativos, no Brasil. Embora seja difícil para os pesquisadores quantificar a contribuição do preconceito etário e da discriminação por idade em si para essas baixas taxas de atividade, muitos indícios não sistemáticos sugerem que tanto homens quanto mulheres, à medida que se aproximam da idade da aposentadoria legal, são cada vez menos inclinados a buscar emprego. Acreditam, com base nas suas próprias experiências, que a discriminação por idade vai pesar contra eles no mercado de trabalho.

Os dados da Pesquisa Mundial de Valores de 2006 mostraram que quase $5 \%$ dos brasileiros, quando perguntados de forma específica se gostariam de ter um idoso como vizinho, responderam negativamente. A boa notícia é que, quando se oferece a possibilidade de 16 diferentes grupos de pessoas como vizinhos potenciais, os idosos 
se encontram entre os menos rejeitados. Ou seja, de cada 100 pessoas perguntadas sobre quais os vizinhos menos desejáveis, as respostas foram por ordem e em cifras arredondadas: os viciados em drogas (20\%), menores infratores e pessoas que bebem demais (15\% cada um), ex-presidiários e prostitutas ( $10 \%$ cada um), homossexuais $(6 \%)$, pessoas com AIDS, doentes mentais e favelados ( $4 \%$ cada um), pessoas que falam uma língua diferente, trabalhadores imigrantes ou estrangeiros, pessoas de outras religiōes e casais não casados mas que moram juntos ( $2 \%$ cada um), pessoas negras e de outras raças $(1,5 \%$ cada um) e, finalmente, os idosos, com precisamente $1,3 \%$.

A discriminação na saúde mostra que, quando se trata dos cuidados médicos apropriados à sua idade, os brasileiros mais velhos tornam-se o seu próprio e pior inimigo. Tal como acontece em outros contextos, os médicos desconsideram certas dores de pessoas mais velhas como parte inevitável do processo de envelhecimento. Não investigam mais profundamente suas causas, tal como fariam com pacientes mais jovens, e o resultado é que muitas pessoas idosas deixam de buscar uma segunda opinião ou mesmo um geriatra, o que pode resultar em morte. Segundo especialistas em saúde, esse fatalismo - e a suposição de que todos, acima dos 60 anos, têm as mesmas necessidades em termos de saúde - tem um nome: preconceito etário médico. Alguns veem este preconceito no amplo fracasso em promover medidas de saúde preventiva ou em lidar com múltiplas doenças crônicas e com o risco de quedas em pacientes mais velhos. Outros apontam para a escassez de idosos em testes de remédios e a falta de vontade dos profissionais de saúde para enfrentar sua própria mortalidade.

O preconceito etário médico no Brasil pode ser exemplificado pelas estatísticas sobre a AIDS, contidas no relatório de 2008 sobre essa epidemia mundial, cujos índices mostram que o número de brasileiras soropositivas com idades entre 50 e 59 anos duplicou entre 2000 e 2007. Este número aumentou em $88 \%$ para as mulheres entre 60 e 69 anos e em 190\%, para as de mais de 70 anos. Embora menos marcada, a tendência entre os homens também mostrou números crescentes. $\mathrm{O}$ aumento agudo da AIDS entre mulheres mais velhas, no Brasil e em alguns outros países da America Latina, ${ }^{13}$ gerou um debate sobre as causas potenciais, que são ilustrativas do preconceito etário. Um grupo importante de causas tem a ver com a vulnerabilidade dessas mulheres, por não estarem mais em idade reprodutiva. Por não haver mais 
risco de gravidez, as preocupaçóes com o uso de preservativos diminuem, fato que se soma ao estagio pós-menopausa, quando as mulheres são mais vulneráveis porque os tecidos vaginais são mais frágeis. Para piorar esse quadro, num contexto marcado por fortes diferenças de gênero, a negociação das mulheres para que os seus parceiros usem preservativos parece ser difícil e menos comum entre casados ou em uniões estáveis.

Finalmente, mesmo numa época em que cresce o uso do Viagra, a suposição parece ser de que as pessoas idosas não são sexualmente ativas e que, misteriosamente, sua sexualidade desaparece a partir de certa idade. Um efeito colateral concreto é o diagnóstico tardio da AIDS entre os idosos e, mesmo quando desenvolvem sintomas da síndrome, o problema permanece oculto sob outras patologias comuns entre a população mais velha. Portanto, quando médicos e pesquisadores menosprezam a sexualidade entre os idosos, não estão ignorando apenas o risco de aumento de outras doenças sexualmente transmissíveis entre este grupo, mas colocando em risco toda a população (ver várias opiniões de especialistas em Valente, 2008).

\section{Perfil da discriminação contra os idosos no Brasil}

“(...) o velho brasileiro não existe. Existem várias realidades de velhice referenciadas a diferentes condições de qualidade de vida individual e social" (Neri, 1993, p. 39).

Não existe um modelo único de envelhecimento no Brasil e vários estudos afirmam a complexidade de traçar um perfil das percepções e atitudes negativas ou positivas sem considerar o contexto das vidas familiar, profissional e pessoal dos indivíduos (Cachioni \& Aguilar, 2008; Freitas et al., 2002). Mudanças nas noções e valores, associadas ao processo de envelhecimento, foram documentadas no Brasil urbano através de artigos na mídia impressa (Neri, 2003). Estas mudanças históricas incluem o envelhecimento numa transição de uma "inquietação divina para uma inquietação mais mundana"; de uma "preocupação masculina para uma preocupação essencialmente feminina”; e da "velhice" para a "terceira idade". Todas essas transiçōes estariam entrelaçadas com novas hierarquias morais e estariam vinculadas à medicalização da velhice no fim do século XX (Leibing, 2004). 
Outros estudos enfatizam as relações intergeracionais e sugerem que existe uma melhoria geral na compreensão entre estas, tanto em termos do status de saúde dos idosos como de atitude dos jovens para com a velhice. Através de interações geralmente agradáveis, jovens e idosos melhoraram sua compreensão e visão uns dos outros. Um exemplo são as percepçóes de alguns grupos de alunos que revelam o quanto se sentem livres para falar com idosos e como os contatos com estes os deixam mais tranquilos (Souza, 2003). A qualidade da relação entre avós e netos também é explorada através da troca de experiências no processo de identidade geracional. Alguns resultados revelaram a importância de uma maior diversidade no meio familiar, na mediação da relação entre jovens (de 15 a 18 anos) e idosos (de 62 a 78 anos), e concluíram que existe uma troca eficiente de conhecimentos, valores e atividades de cuidados entre os dois grupos (Schmidth, 2007).

Apenas um estudo brasileiro recente compara resultados de pesquisas internacionais sobre preconceito etário com dados para o sul do Brasil (Couto et al., 2009). Identificando os tipos predominantes de discriminação contra pessoas mais velhas e medindo as relações destas com os níveis de estresse, este estudo baseou-se em questionários semelhantes aos que foram aplicados em Portugal e nos Estados Unidos. Usando um indicador sumário de preconceito etário que se baseia na frequência e no tipo de discriminação e no nível de estresse associado, os resultados mostram que o preconceito etário não é diferenciado por sexo, anos de escolaridade e nem pela autoavaliação de saúde. Contudo, o nível deste preconceito é maior nos casos em que os idosos estão menos satisfeitos com seu status socioeconômico.

Ao contrário das expectativas dos autores, os níveis médios de estresse na maioria das situações de discriminação foram muito baixos. Estes sugerem que a experiência de discriminação não estaria necessariamente associada ao estresse e que os idosos, neste estudo, poderiam estar usando diferentes estratégias para lidar com a discriminação negativa. Nesse sentido, os autores chamam a atenção para a natureza de sua amostra não representativa. As organizações (grupos da terceira idade) amostradas organizavam atividades e conferências para estimular os idosos a pensarem positivamente sobre a sua idade. Isso poderia ter aumentado a autoestima e facilitado aos idosos lidarem com os preconceitos, fatos que teriam contribuído para diminuir o risco de estresse neste grupo (Couto et al., 2009). 
As comparações nacionais sobre o preconceito etário entre os idosos mostram tanto diferenças quanto semelhanças com Portugal e os Estados Unidos. As semelhanças entre experiências de discriminação por idade foram maiores entre brasileiros e portugueses do que entre brasileiros e norte-americanos. Os maiores níveis de violência foram sofridos por idosos brasileiros, o que é compatível com os maiores níveis de violência no país. Em conclusão, apesar de certos problemas de comparação (a amostra não contempla o Brasil inteiro e selecionou pessoas com melhor saúde e ativas em grupos de terceira idade), os autores apontam que os tipos de discriminação mais comuns estão relacionados ao contexto social e à saúde dos indivíduos e reforçam a tese do preconceito etário como um fenômeno generalizado e transcultural.

\section{Conclusão}

O crescente envelhecimento demográfico e o formato das atuais políticas públicas brasileiras colocam o preconceito etário como tema obrigatório na agenda de todos aqueles interessados em promover uma cidadania ampla e uma sociedade para todas as idades. O termo "preconceito etário" não parece ser muito conhecido entre os brasileiros e sua discussão ainda se restringe ao meio acadêmico. Entretanto, ainda que não explicitados, os aspectos positivos e negativos desta forma de preconceito foram incorporados às políticas governamentais nas últimas duas décadas. Consistente com um modelo histórico de políticas públicas, estratificado por idade e sexo e estimulado pela assinatura oficial de acordos internacionais e por sua nova Constituição, o Brasil incorporou uma série de novos estatutos legais nos anos de 1990.

O Estatuto do Idoso e o Estatuto da Criança e do Adolescente, por exemplo, tratam do universo mais específico vinculado ao tratamento social e legal que deve ser oferecido aos seus membros. Dentro de um espírito de maior proteção e cidadania, decorrentes da Constituição promulgada em 1988, estes instrumentos legais estabelecem limites de idades para os beneficiários e, assim, deixam claro um perfil de idades apropriadas e as expectativas para diferentes estágios de vida individual e familiar. Insistimos que noticiar a idade de alguém não é inerentemente ofensivo, mas agir a partir de estereótipos baseados na idade é claramente preconceituoso e vale a pena considerar este aspecto quando se discute políticas. 
A discriminação por idade e os estereótipos são problemas que a sociedade, se seus membros estão buscando uma igualdade universal, deve tratar de eliminar através de conscientização e da educação (Garstka et al., 2004). Para combater o preconceito etário, uma questão inicial importante a responder seria "Para que servem os idosos?". No contexto brasileiro, isso exige levar em conta tanto o aumento sem precedentes da população idosa, como os pressupostos comuns sobre idosos. Por exemplo, se os idosos forem vistos apenas como item de despesa nos orçamentos de benefícios, então o alarme dos responsáveis por políticas e os discursos de alguns economistas a respeito dos custos da Previdência e do futuro passam a fazer sentido. Por outro lado, se a resposta à pergunta "Para que servem os idosos?" levar em conta a contribuiçãao efetiva das pessoas mais velhas para a produção e reprodução da sociedade, então não podemos planejar uma comunidade residencial que se baseie apenas na ideia de "entrega de serviços", por mais eficiente que seja. Neste caso, o argumento seria de que o processo de envelhecimento das novas geraçôes será diferente e que os "novos idosos" desafiarão os estereótipos de uma sociedade envelhecida, particularmente o sentimento melancólico de que a velhice não passa de declínio (Edgar, 1991; Thomas, 2004).

Portanto, o uso de várias perspectivas para entender o envelhecimento e seus impactos é muito importante para guiar políticas e, sobretudo, para garantir direitos e bem-estar aos indivíduos. Argumentamos que, no Brasil, as inequidades e necessidades da população deveriam ser vistas no quadro maior das mudanças de expectativas, atitudes e políticas sociais vigentes. $\mathrm{O}$ alarmismo de que uma sociedade que envelhece aumenta o grau de dependência deveria ser contraposto com alguns fatos menos difundidos, tais como a participação crescente de mulheres na mão de obra, a vasta quantidade de ajuda intergeracional recíproca presente nas famílias brasileiras, a renda que os idosos costumam fornecer às famílias e o fato de que, cada vez mais, adultos já criados voltam a morar com seus pais. As relações entre idosos e jovens também não deveriam ser consideradas meramente em termos econômicos ou de trocas de ajuda, mas em termos de seus laços afetivos e emocionais. De fato, o aumento da longevidade tem permitido descrever as trocas entre as geraçôes como parte de uma nova forma de família estendida, baseada na "intimidade a distância". Desse modo, novas tendências e abordagens exigem que a noção de "dependência" 
seja vista sob uma perspectiva maior ou, como sugerimos para o Brasil, que ultrapasse a simples relação entre mudanças demográficas e custos econômicos dos serviços públicos.

Finalmente, reconhecer o preconceito etário como um problema é o primeiro passo para eliminá-lo. O próximo consiste em escolher um método para combatê-lo e conscientizar os indivíduos a respeito das suas consequências. Uma herança duradoura das relaçóes familiares, no contexto de vidas cada vez mais longas, emerge como parte importante desse processo. Nesse sentido, sugerimos que algumas das áreas necessitadas de uma compreensão mais profunda seriam: a dos novos arranjos e vínculos permitidos pela longevidade e pelas maiores probabilidades de convivências, de como o conhecimento é transmitido entre as gerações e dentro delas; do papel da biologia, ou seja, das interações entre gene e meio ambiente, e das relações entre biologia e cultura; e do estudo das mudanças ocorridas entre e dentro das geraçôes, em termos de acesso aos recursos culturais e materiais. Finalmente, advogamos a necessidade de se pensar em uma legislação que elimine a discriminação por idade em diferentes setores e não apenas no emprego, tal como foi proposto recentemente na União Europeia.

\section{Recebido em maio de 2010 e aprovado em junho de 2010}

\section{Notas}

1. Resposta de Fabio Zonzini à entrevista "Descalça, Ana Botafogo fala em despedida", de Adriana Pavlova, na Folha de S. Paulo on-line, em 09/04/2010. A jornalista mencionou que Botafogo não quis revelar a sua idade, mas que estava dançando havia 35 anos.

2. A Lei da Igualdade, de 2009 , que visa a consolidar e, até certo ponto, modernizar e clarificar a legislação existente contra a discriminação em todos os campos protegidos, está gerando um debate polêmico. Na Inglaterra, por exemplo, alguns líderes religiosos opõemse ao fato de que a legislação existente restringe a liberdade de discriminar alguém por sua orientação sexual com base nas crenças religiosas do discriminador (Flash Report, 2009).

3. Embora preconceito etário e discriminação por idade costumem ser considerados como sinônimos, o fato é que o primeiro remete essencialmente ao sistema de atitudes, muitas vezes atribuídas por indivíduos e pela sociedade a outros em função da idade, enquanto a discriminação por idade descreve comportamentos que favorecem pessoas de determinada idade.

4. N. do T.: A tradução literal da palavra inglesa "ageism" seria "idadismo" ou "edaismo". Como o neologismo não foi adotado em português, preferiu-se "preconceito etário".

5. Uma abordagem por gênero da discriminação por idade aponta para o mercado de trabalho, onde o emprego segue a cronologia mais valorizada, masculina, de desenvolvimento 
de carreira e de emprego contínuo. Além do mais, estudos recentes notam que nosso desconhecimento dos aspectos comportamentais referentes à masculinidade dos indivíduos mais velhos está arraigado em práticas de preconceito etário. Diferentemente das discussôes de masculinidade e classe, etnicidade, sexualidade, ou pano de fundo religioso, o envelhecimento foi raramente levado em conta quando se discute masculinidades. Assim como a feminilidade tem sido um parâmetro, definindo as fronteiras do que a masculinidade não é, durante os dois últimos séculos, o "velho" também foi incorporado como medidor cultural para o que a masculinidade não é (Kimmel, 1997; Thompson \& Whearty, 2004; Davidson, 2004).

6. Existem diferentes perspectivas sobre as relações intergeracionais no discurso público e nas decisões políticas. Os grupos políticos formulam o debate em termos de "benefícios" baseados na idade, de modo que podem ser favoráveis ou não às iniciativas de despesas sociais (Quadagno, Aschenbaum \& Bengston, 1993). Estudos recentes estão investigando as perspectivas para aumentar a idade média da aposentadoria e consideram o desafio de garantir uma aposentadoria segura para trabalhadores com baixos salários ou que estejam incapacitados (Munnel \& Saas, 2008).

7. Turra e Queiroz colocaram-se a pergunta: o quanto as políticas públicas e as instituições melhoraram as condições financeiras (a suficiência financeira) do sistema previdenciário na última década? Demograficamente, as taxas de fecundidade total caíram de 5,3 para 2,1 filhos por mulher, entre 1970 e 2000, e diminuiu ainda mais: 1,9 filhos em 2008. A expectativa de vida para ambos os sexos no mesmo período aumentou de 57,5 para 70,3 anos e atingiu 72,7 anos em 2008 (IBGE, 2008, 2009).

8. Um modelo estatístico de regressão do tipo "Probit" foi utilizado. Por questão de espaço, as tabelas não foram anexadas aqui.

9. Outro fator contextual que cabe mencionar é a criação do Conselho Nacional dos Direitos do Idoso, resultante dos esforços do governo para reduzir as desigualdades sociais entre pessoas idosas, nos anos de 1990. Estes esforços culminaram na criação do "Estatuto do Idoso", cujo projeto original (Lei n. 3.561) remonta a 1997, mas que só acabou sendo aprovado em 2006.

10. É importante notar que a maioria das famílias brasileiras que recebem benefícios de programas sociais, tais como o de Benefício de Prestação Continuada ou o Programa de Erradicação do Trabalho Infantil, são chefiadas por uma pessoa negra $(60 \%$ e $68 \%$, respectivamente). Ver, a respeito, Pinheiro et al. (2008).

11. No cerne desse debate está o fato de saber se o financiamento de programas sociais que beneficiam grupos etários particulares deveria ser eliminado. Apelos para a "equidade geracional”, por exemplo, podem ser vistos como estratégias políticas para legitimar reduções nas despesas do governo.

12. Essa abordagem é amplamente usada como um ideal para analisar a discriminação por idade em cuidados sociais para adultos financiados publicamente. Para Sen (1999), todas as pessoas deveriam ter asseguradas as mesmas liberdades substantivas. Ou seja, que as pessoas disponham das mesmas capacidades para alcançarem os resultados desejados. Portanto, o nível de desigualdade seria medido em termos das diferenças em capacidades entre os grupos etários.

13. No Chile, $10 \%$ dos casos soropositivos estão entre adultos mais velhos e os números estão crescendo, segundo Juan Molina. No México, onde a prevalência da AIDS é inferior à maior parte dos outros países latino-americanos, $11,7 \%$ dos casos soropositivos estão entre pessoas acima de 45 anos, segundo o Centro Nacional de Prevenção e Controle do HIV/ AIDS (CENSIDA) (Valente, 2008).

Educ. Soc., Campinas, v. 31, n. 111, p. 411-434, abr.-jun. 2010

Disponível em <http://www.cedes.unicamp.br> 


\section{Referências}

BARROS, R.P.; CARVALHO, M. Desafios para a politica social brasileira. Rio de Janeiro: IPEA, 2003. (Textos para discussão, n. 985).

BARROS, R.P.; MENDONCA, R.; SANTOS, D. Incidência e natureza da pobreza entre idosos no Brasil. In: Camarano, A.A. (Org.). Muito além dos 60: os novos idosos brasileiros. Rio de Janeiro: IPEA, 1999. p. 221-250.

BUTLER, R. Ageism: a foreword. Journal of Social Issues, Washington, DC, v. 36, n. 2, p. 8-11, 1980.

BYTHEWAY, B. Ageism and age categorization. Journal of Social Issues, Washington, DC, v. 61, n. 2, p. 361-374, 2005.

CACHIONI, M.; AGUILLAR, L.E. Crenças em relação à velhice entre alunos da graduação, funcionários e coordenadores envolvidos com as demandas da velhice em universidades brasileiras. Kairós, São Paulo, v. 2, n. 11, p. 95-119, 2008.

CAMARANO, A.A. (Org.). The new sixties in Brazil: the elderly Brazilians and their new social roles. Rio de Janeiro: IPEA, 2005.

COLLINS, P.H. Black feminist thought: knowledge, consciousness, and the politics of empowerment. New York: Routledge, 2000.

COUTO, M.C.P. et al. Avaliação de discriminação contra idosos em contexto brasileiro: ageismo. Teoria \& Pesquisa, Brasília, DF, v. 25, n. 4, p. 509-518, out./dez. 2009.

CRENSHAW, K. Mapping the margins: intersectional, identity politics and violence against women of color. In: CRENSHAW, K. et al. (Ed.). Critical race theory: the writtings that formed the movement. New York: New York University, 1995. p. 363-377.

DAVIDSON, K. Why can't a man be more like a woman?: marital status and social networking of older men. The Journal of Men's Studies, Harriman, TN, v. 13, n. 1, p. 25-43, Sept. 2004.

DEBERT, G.G. A reinvenção da velhice: socialização e processos de reprivatização do envelhecimento. São Paulo: FAPESP, 1999. 
EDGAR, D. Ageing: everybody's future. Family Matters, Melbourne, n. 30, p. 15-19, Dec. 1991.

ESPING-ANDERSEN, S.S. et al. The generational conflict reconsidered. Journal of European Social Policy, London, v. 12, n. 1, p. 5-21, 2002.

FLASH REPORT. UK-24-UK Equality Bill 2009. European network of legal experts in the non-discrimination field. 2009. (on-line).

FREITAS, E.V. et al. (Org.). Tratado de geriatria e gerontologia. Rio de Janeiro: Guanabara; Koogan, 2002.

GARSTKA, T.A. et al. How young and older adults differ in their responses to perceived age discrimination. Psychology of Aging, Washington, DC, v. 19, n. 2, p. 326-335, 2004.

GARSTKA, T.A.; HUMMERT, M.L.; BRANSCOMBE, N.R. Intergenerational inequity. Journal of Social Issues, Washington, DC, v. 61, n. 2, p. 321-342, 2005.

GIAMBIAGI, F. Diagnóstico da Previdência Social no Brasil: o que foi feito e o que falta reformar. Rio de Janeiro: IPEA, 2004. (Seminário DIMAC, n.164).

GOLDANI, A.M. Intergenerational contracts and the reconstruction of the welfare State: why should we re-think this relationship in Brazil? In: Camarano, A.A. (Org.). The new sixties in Brazil: the elderly Brazilians and their new social roles. Rio de Janeiro: IPEA, 2005. p. 211-252.

INSTITUTO BRASILEIRO DE GEOGRAFIA E ESTATÍSTICA (IBGE). Projeção da população do Brasil: população brasileira envelhece em ritmo acelerado. Comunicação Social, Brasília, DF, 27 nov. 2008. Disponível em: <http://www.ibge.gov.br>

INSTITUTO BRASILEIRO DE GEOGRAFIA E ESTATÍSTICA (IBGE). Complete mortality tables 2008: life expectancy of Brazilians reached 72.86 years of age. Social Communication, Rio de Janeiro, Dec. 1, 2009. Disponível em: <www.ibge.gov.br>

KIMMEL, M. Manhood in America. New York: Free, 1997. 
LAVINAS, L.; GARSON, S. Gasto social no Brasil: transparência, sem participação. Econômica, Rio de Janeiro, v. 5, n. 1, p. 145-162, jun. 2003.

LEIBING, A. The old lady from Ipanema: changing notions of old age in Brazil. Rio de Janeiro: Instituto de Psiquiatria; UfRJ, 2004.

MACNICOL, J. Age discrimination: an historical and contemporary analysis. Cambridge: Cambridge University, 2006.

MUNNELL, A.; SAAS, S.A. Working longer: the solution to the retirement income challenge. Washington, DC: The Brookings Institution, 2008.

NERI, A.L. Qualidade de vida no adulto maduro: interpretações teóricas e evidências de pesquisa. In: NerI, A.L. Qualidade de vida e idade madura. Campinas: Papirus, 1993. p. 9-55.

NERI, A.L. Atitudes em relação à velhice: questões científicas e políticas. In: Freitas, E.V. et al. Tratado de geriatria e gerontologia. Rio de Janeiro: Guanabara, 2002

NERI, A.L. Atitudes e crenças sobre velhice: análise de conteúdo de textos do jornal O Estado de S. Paulo publicados entre 1995 e 2002. In: von Simson, O.R.M.; Neri, A.L.; Cachioni M. (Org.). As múltiplas faces da velhice no Brasil. Campinas: Átomo \& Alínea, 2003. p. 13-54.

NERI, A.L. Palavras-chave em gerontologia. Campinas: Alínea, 2005.

PALMORE, E.B. Research note: ageism in Canada and the United States. Journal of Cross-Cultural Gerontology, New York, n. 19, p. 4146, 2004.

PINHEIRO, L. et al. Retrato das desigualdades de gênero e raça. Brasília, DF: IPEA; SPM; UNIFEM, 2008.

QUADAGNO, J.; ASCHENBAUM, A.; BENGSTON, V.L. Editing the agenda of research on chorts and generations: theoretical, political and policy implications. In: Bengston, V.I.; Aschenbaum, A. (Ed.). The changing contract across generations. New York: Aldine De Gruyter, 1993. 
SAMPAIO, R.F.; NAVARRO, A.G.; MARTÍN, M.M. Work-related disabilities and worker's disabilities in rejoining the labor market. Cadernos de Saúde Pública, Rio de Janeiro, v. 15, n. 4, p. 809-815, out./dez. 1999.

SARGEANT, M. The law on age discrimination in the EU. The Netherland: Kluwer, 2008.

SEN, A. Capability and well-being. In: Nussbaum, M.C.; Sen, A. (Ed.). The quality of life. Oxford: Clarenden, 1999. p. 50-68.

SEN, A. Reason, freedom and well-being. Utilitas, Cambridge, v. 18, n. 1, p. 80-96, 2006.

SOUZA, E.M. Integração entre gerações na promoção da saúde: estudo qualitativo no Brasil. Revista de Saúde Pública, São Paulo, v. 37, n. 4, p. 463-469, 2003. Disponível em: http://www.scielo.br/rsp

THOMAS, W.H. What Are old people for?: how elders will save the world. Acton, MA: Vanderwyk \& Burnham, 2004.

THOMPSON JUNIOR, E.H.; WHEARTY, P.M. Older men's social participation: the importance of masculinity ideology. The Journal of Men's Studies, Harriman, TN, v. 13, n. 1, p. 5-24, Sept. 2004.

TOWSEND-BELL, E. Intersectional praxis. Paper presented at the American Political Science Association Annual Meeting. Toronto, Canada, 2009.

TURRA, C.M.; QUEIROZ, B.L. Antes de que sea demasiado tarde: transición demográfica, mano de obra disponible y problemas de la seguridad social en el Brasil. Notas de Población, Santiago de Chile, n. 86, CEPAL, n. 86, p. 141-165, LC/G2349-P, 2009.

VALENTE, M. AIDS-Latin America: neglect, 'ageism' put older people at risk. Inter Press Service English News Wire Article. Dec. 29, 2008. Disponível em: <www.banderasnews.com>

VELOZ, M.C.T.; NASCIMENTO-SCHULZE, C.M.; CAMARGO, B.V. Representações sociais do envelhecimento. Psicologia: Reflexão e Crítica, Porto Alegre, n. 12, p. 479-501, 1999. 
VON SIMSON, O.R.M.; NERI, A.L.; CACHIONI, M. (Ed.). As múltiplas faces da velhice no Brasil. Campinas: Átomo \& Alínea, 2003. WAJNMAN, S.L. et al. The capital for the old age. In: CAMARANO, A.A. (Org.). The new sixties in Brazil: the elderly Brazilians and their new social roles. Rio de Janeiro: IPEA, 2005. p. 439-464. 